Nixon Manuel Ortega-Carchipulla; Jaime Tinto-Arandes; Judith Cristina Pesantez-Rodriguez;

Edwin Joselito Vásquez-Erazo

http://dx.doi.org/10.35381/r.k.v5i3.898

\title{
Gestión del riesgo de LA/FT y lógica difusa en bancos con calificación AA factor cliente
}

\section{ML / TF risk management and fuzzy logic in banks rated AA customer factor}

\author{
Nixon Manuel Ortega-Carchipulla \\ nixon.ortega@psg.ucacue.edu.ec \\ Universidad Católica de Cuenca, Cuenca \\ Ecuador \\ https://orcid.org/0000-0003-2174-6699 \\ Jaime Tinto-Arandes \\ itinto@ucacue.edu.ec \\ Universidad Católica de Cuenca, Cuenca \\ Ecuador \\ https://orcid.org/0000-0001-8507-6837 \\ Judith Cristina Pesantez-Rodriguez \\ jcpesantezr@ucacue.edu.ec \\ Universidad Católica de Cuenca, Cuenca \\ Ecuador \\ https://orcid.org/0000-0002-9058-6695 \\ Edwin Joselito Vásquez-Erazo \\ evasqueze@ucacue.edu.ec \\ Universidad Católica de Cuenca, Cuenca \\ Ecuador \\ https://orcid.org/0000-0001-9817-6773
}

Recibido: 20 de mayo de 2020

Revisado: 15 de junio de 2020

Aprobado: 30 de julio de 2020

Publicado: 15 de agosto de 2020 
Nixon Manuel Ortega-Carchipulla; Jaime Tinto-Arandes; Judith Cristina Pesantez-Rodriguez; Edwin Joselito Vásquez-Erazo

\title{
RESUMEN
}

La investigación tiene por objetivo analizar la gestión del riesgo de LA/FT y lógica difusa en bancos con calificación AA factor cliente. Metodológicamente se desarrolló un tipo descriptiva. Como resultado de las encuestas realizadas se puede evidenciar que existen deficiencias para cumplir una de las políticas más importantes cómo es, la política conozca a su cliente, como consecuencia de las debilidades identificadas se presentan las siguientes incidencias: Inadecuada definición de perfil de riesgo de los clientes, generación de alertas falsas en el sistema por falta de información de los clientes, dificultad de los oficiales de negocios en la aplicación de las debidas diligencias de los clientes, carga operativa en el seguimiento de operaciones que no ameriten un análisis. Las políticas y procedimientos del manual de lavado de activos y financiamiento de delitos como el terrorismo deben estar involucrados todos los funcionarios de las instituciones financieras.

Descriptores: Terrorismo; instituciones financieras; dispositivo de seguridad; prevención del crimen. (Palabras Tomadas del Tesauro UNESCO).

\begin{abstract}
The research aims to analyze ML / TF risk management and fuzzy logic in banks with AA customer factor rating. Methodologically, a descriptive type was developed. As a result of the surveys carried out, it can be evidenced that there are deficiencies in complying with one of the most important policies, how it is, the policy know your client, as a consequence of the weaknesses identified, the following incidents are presented: Inadequate definition of the risk profile of the clients, generation of false alerts in the system due to lack of information from clients, difficulty for business officers in applying due diligence from clients, operational burden in monitoring operations that do not merit analysis. The policies and procedures of the manual on money laundering and financing of crimes such as terrorism must involve all officials of financial institutions.
\end{abstract}

Descriptors: Terrorism; banks; safety devices; crime prevention. (Words Taken from the UNESCO Thesaurus). 
Nixon Manuel Ortega-Carchipulla; Jaime Tinto-Arandes; Judith Cristina Pesantez-Rodriguez; Edwin Joselito Vásquez-Erazo

\section{INTRODUCCIÓN}

El sistema financiero en el Ecuador es fundamental ya que desempeña un papel muy importante en la economía del país mediante captación del dinero del público en moneda nacional y extranjera en forma habitual o continúa, en este sentido, (Romero, 2015) menciona que en el Ecuador podemos encontrar entidades financieras privadas como: cooperativas, bancos, mutualistas y sociedades financieras, además tenemos compañías de seguros y compañías de apoyo del sistema financiero, instituciones de servicios financieros y entidades financieras públicas.

La (Superintendencia de Bancos, 2019) señala que los bancos representan el mayor porcentaje de participación en el medio, abarcando más del $90 \%$ del total de las operaciones del sistema. Dentro de la provincia del Azuay se encuentran 15 Bancos Financieros, públicos como privados: Banco Produbanco - Grupo Promerica, Banco del Pacífico S.A., Banco Internacional S.A., Banco de Desarrollo del Ecuador B.P. Sucursal Zonal del Austro, Banco Bolivariano, Banco del Austro S.A., Banco Desarrollo de los Pueblos S.A., Banco de Guayaquil S.A., Banco Solidario, Banco del less - BIESS, Banco Capital S. A., Banco de Machala S.A., Banco Pichincha C.A., Banecuador, Banco Procredit S.A.

Así mismo, la (Superintendencia de Bancos, 2019) dio a conocer la calificación de riesgos de las entidades financieras en junio del 2019, por la cual se especifica por escalas la calificación de bancos que se encuentra dentro de la provincia del Azuay: 
Nixon Manuel Ortega-Carchipulla; Jaime Tinto-Arandes; Judith Cristina Pesantez-Rodriguez; Edwin Joselito Vásquez-Erazo

Tabla 1.

Calificación de riesgo de bancos financieros AAA.

\begin{tabular}{|c|c|c|}
\hline Instituciones financieras & $\begin{array}{c}\text { Firma de calificador de } \\
\text { riesgo }\end{array}$ & Calificación a junio 2019 \\
\hline $\begin{array}{l}\text { Banco de la Producción } \\
\text { s.a. Produbanco }\end{array}$ & $\begin{array}{l}\text { Pcr pacific s.a. /Bank } \\
\text { watch ratings s.a. }\end{array}$ & AAA- /AAA- \\
\hline Banco del Pacifico S.A. & Pcr pacific s.a. & AAA \\
\hline $\begin{array}{l}\text { Banco Internacional } \\
\text { S.A. }\end{array}$ & $\begin{array}{c}\text { Bank watch ratings s.a. / } \\
\text { Class international } \\
\text { rating }\end{array}$ & AAA- / AAA \\
\hline $\begin{array}{l}\text { Banco de Desarrollo del } \\
\text { Ecuador }\end{array}$ & Pcr pacific s.a. & AAA- \\
\hline Banco Bolivariano C.A. & $\begin{array}{l}\text { Pcr pacific s.a. / Bank } \\
\text { watch ratings s.a. }\end{array}$ & AAA /IAAA- \\
\hline $\begin{array}{l}\text { Banco de Guayaquil } \\
\text { C.A. }\end{array}$ & $\begin{array}{c}\text { Pcr pacific s.a. / Soc. } \\
\text { cal. riesgo } \\
\text { latinoamericana }\end{array}$ & AAA /IAAA \\
\hline Banco Pichincha C.A. & $\begin{array}{l}\text { Pcr pacific s.a. / Bank } \\
\text { watch ratings s.a. }\end{array}$ & AAA- /IAAA- \\
\hline Biess Banco del IESS & $\begin{array}{c}\text { Class international } \\
\text { rating }\end{array}$ & AAA-I \\
\hline Banco Procredit S.A. & $\begin{array}{l}\text { Pcr pacific s.a. / Bank } \\
\text { watch ratings s.a. }\end{array}$ & AAA- / AAA- \\
\hline
\end{tabular}

Fuente: Superintendencia de Bancos (2019).

Los bancos que se encuentran en la escala AAA tienen un muy buen renombre en el medio, son instituciones con años de altos rendimientos, fácil acceso a sus mercados naturales de capital y fuertes señales de estabilidad, mismas que permitirán sobrellevar contratiempos en caso de algún imprevisto (Superintendencia de Bancos, 2019). 
Nixon Manuel Ortega-Carchipulla; Jaime Tinto-Arandes; Judith Cristina Pesantez-Rodriguez; Edwin Joselito Vásquez-Erazo

\section{Tabla 2.}

Calificación de riesgo de bancos financieros $A A$.

\begin{tabular}{|c|c|c|}
\hline $\begin{array}{l}\text { Instituciones } \\
\text { financieras }\end{array}$ & $\begin{array}{c}\text { Firma de calificador de } \\
\text { riesgo }\end{array}$ & $\begin{array}{c}\text { Calificación a junio } \\
2019 \\
\end{array}$ \\
\hline Banco del Austro S.A. & $\begin{array}{l}\text { Pcropacific s.a. / } \\
\text { Summa rating s.a. }\end{array}$ & $\mathrm{AA} / \mathrm{AA+}$ \\
\hline Banco de Machala S.A. & $\begin{array}{c}\text { Class international } \\
\text { rating }\end{array}$ & $\mathrm{AA}+$ \\
\hline Banco Solidario S.A. & $\begin{array}{c}\text { Class international } \\
\text { rating / Bank watch } \\
\text { ratings s.a. }\end{array}$ & *1/AA+ \\
\hline
\end{tabular}

Fuente: Superintendencia de Bancos (2019).

Los bancos que se encuentran en la escala AA tienen un alto índice de solidez, buenas referencias de utilidad y no presentan debilidades financieras (Superintendencia de Bancos, 2019). En la ciudad de Cuenca se encuentran los Bancos financieros privados con categoría AA: Bancos del Austro S.A., Banco de Machala S.A., Banco Solidario S.A., las entidades financieras mencionadas tienen capacidad muy fuerte para cumplir con sus compromisos financieros. Este emisor difiere solamente en un pequeño grado de los que tienen la calificación más alta. Los problemas que tienen estas entidades es que ni cuentan con información necesaria para realizar un análisis exhaustivo del usuario financiero, ocasionando ingresos de dinero procedente de operaciones ilícitas ya sea en moneda nacional o extranjera, por esto se desarrollará un plan de administración de riesgo para prevenir el ingreso de dinero ilegal y financiamiento del terrorismo bajo el enfoque de la lógica difusa. 
Nixon Manuel Ortega-Carchipulla; Jaime Tinto-Arandes; Judith Cristina Pesantez-Rodriguez; Edwin Joselito Vásquez-Erazo

\section{Tabla 3.}

Calificación de riesgos de bancos financieros $A, B B B, C$.

\begin{tabular}{lcc}
\hline Instituciones financieras & $\begin{array}{c}\text { Firma de calificador de } \\
\text { riesgo }\end{array}$ & Calificación a junio 2019 \\
\hline $\begin{array}{l}\text { Banco Desarrollo de los } \\
\text { Pueblo S.A. }\end{array}$ & $\begin{array}{c}\text { Micro finanza rating s.a. } \\
\text { Banco Capital S.A. }\end{array}$ & BBB+ \\
Banecuador & $\begin{array}{c}\text { Plass international } \\
\text { rating }\end{array}$ & C \\
\hline
\end{tabular}

Fuente: Superintendencia de Bancos (2019).

En la categoría "A" encontramos a Banecuador, esta institución presenta récord financiero limpio y con solidez, además, no presenta contratiempos en sus mercados naturales de dinero. En la BBB, encontramos al Banco de desarrollo del pueblo S.A. que notoriamente posee crédito alto, no obstante, presenta algunos inconvenientes menores que no son de gran importancia y pueden manejarse en un periodo corto de tiempo, y en el C encontramos al Banco Capital S.A. que muestra índices financieros que sugieren notables deficiencias, posiblemente afines a una mala estructuración del balance o a la calidad de los activos de la institución. Figura un futuro con mucha incertidumbre y escasa capacidad para hacer frente a imprevistos (Superintendencia de Bancos, 2019).

En función de lo planteado, la investigación tiene por objetivo analizar la gestión del riesgo de LA/FT y lógica difusa en bancos con calificación AA factor cliente en la ciudad de Cuenca - Ecuador. 
Nixon Manuel Ortega-Carchipulla; Jaime Tinto-Arandes; Judith Cristina Pesantez-Rodriguez; Edwin Joselito Vásquez-Erazo

\section{Referencial teórico}

\section{Administración de riesgo de prevención de lavado de activos en las entidades financieras}

En la actualidad, las empresas están cada vez más conscientes de los riesgos que pueden surgir a partir de sus actividades. A medida que las mismas van acumulando recursos financieros, activos intangibles y tangibles, incrementará su exposición a diferentes eventos, amenazas y vulnerabilidades, ante esto, la gestión del riesgo representa una armadura corporativa para un desarrollo adecuado (Soler-González, et al., 2018). En concordancia a esto (Díaz-Córdova, et al., 2017), indican que una gestión adecuada del riesgo permitirá conocer el desempeño empresarial, a través de la evaluación de los estados financieros, dando como resultado la salud financiera. Los tipos de riesgo más comunes según Grijalva (2016) son:

1. Factores de riesgo del cliente:

1.1. Bancos: el GAFI monitorea y controla el desarrollo de actividades ilícitas conforme a ciertas sugerencias que presentan a los bancos para combatir estas prácticas.

1.2. Empresas públicas: cotizan en bolsa y son sujetas a la divulgación en lo que respecta a su información debido a que tienen la obligación de ser transparentes.

2. Administraciones públicas o empresas:

2.1. Factores de riesgo del producto, servicio, transacción o canal de entrega: Productos o servicios financieros que lleva a cabo sus actividades adecuadamente definidos y limitados servicios a ciertos tipos de clientes, para aumentar el acceso a servicios financieros.

3. Factores de riesgo país:

3.1. Este concepto hace referencia a naciones reconocidas por fuentes fidedignas que poseen bajo nivel de corrupción u otra actividad criminal, al hacer una evaluación de riesgos, países o finanzas hay que tener en cuenta posibles variaciones en riesgo de lavado de dinero y financiamiento del terrorismo entre diferentes regiones o áreas dentro de un país. 
Nixon Manuel Ortega-Carchipulla; Jaime Tinto-Arandes; Judith Cristina Pesantez-Rodriguez; Edwin Joselito Vásquez-Erazo

Según lo indicado en el párrafo anterior, se aprecia que una gestión adecuada del riesgo involucra el estudio de varias categorías como lo son: riesgo del cliente, administración pública o empresarial, riesgo país, para conocer esta información, (Amores, 2016) considera que se necesita admitir que las entidades financieras empleen mecanismos de supervisión y control proporcionalmente al nivel de riesgo detectado, para esto se debe tomar en cuenta los siguientes parámetros como: cliente, clase de productos, posicione geográfica y servicios que forman parte de su actividad económica.

Por tanto, se necesita conocer el riesgo al que se enfrentan las empresas o instituciones para identificar actividades ilícitas, la más común a nivel local e internacional es el lavado de dinero, la palabra "lavado" según lo indica (Uribe, 2003) se origina en los años 20 en EEUU cuando las mafias norteamericanas implementaron negocios de lavanderías para encubrir la procedencia del dinero ilícito producto de sus actividades ligadas al crimen, sus ganancias eran justificadas por el negocio de las lavanderías. Esta actividad ha dado lugar al financiamiento del terrorismo (Martínez, 2015) lo define como cualquier tipo de operación económica ilícita que dé soporte financiero a las acciones de agrupaciones terroristas.

La administración del riesgo para detectar el blanqueo de capital y financiamiento del terrorismo según (Grijalva, 2016) tiene la finalidad de permitir a las entidades financieras establecer políticas y procedimientos adecuados para evitar su utilización inadecuada de fondos para costear actividades delictivas. Por esto, es necesario que la gerencia de cada empresa o institución participe activamente en el análisis y reconocimiento de los riesgos para tomar medidas de control, partiendo del conocimiento exhaustivo de sus clientes.

El lavado de activos y el financiamiento del terrorismo son 2 riesgos a los que son expuestas las compañías de todas las secciones económicas, (Mariño, et al, 2014) acotan que los mismos incurren en pérdida o daño a la que se enfrenta una empresa o institución financiera, pues suelen estar utilizadas indirectamente como instrumento para lavado de activos, estos riesgos intrínseco pueden manifestarse desde los enfoques: legal, reputacional, operativo y de contagio, afectando su estabilidad 
Nixon Manuel Ortega-Carchipulla; Jaime Tinto-Arandes; Judith Cristina Pesantez-Rodriguez; Edwin Joselito Vásquez-Erazo

financiera. Las cifras en lo que tiene que ver con el lavado de dinero puede representar el 7\% PIB mundial, sus cifras en el mundo oscilan entre 800 mil millones y 2 billones de dólares. Los riesgos asociados al lavado de activos y al financiamiento de terrorismo se presentan en la siguiente tipología como lo indican (Cruz-Martínez \& Alarcón-Armenteros, 2017):

1. Riesgo reputación: hace referencia a la mala reputación, figura, divulgación negativa, verídica o no, a la que se encuentra expuesta la empresa o institución lo que repercute en la pérdida de clientela y por lo tanto, la disminución en sus ingresos.

2. Riesgo legal: la empresa o institución se expone a la sanción como consecuencia del incumplimiento de normas y contratos previamente establecidos.

3. Riesgo de Contagio: es la probabilidad de pérdida por acción o vivencia de un afín o asociado de la institución.

Por su parte, (Puente, 2018) indica que el lavado de activos persigue el objetivo de integrarse a la economía formal, mediante transacciones realizadas por terceras personas cuyos negocios manejan altas sumas de dinero, de este modo se aparenta la legalidad en las ganancias. Existen diversas formas para el lavado de dinero, así lo indica Bermeo (2015):

1. Fraccionamiento: el dinero es introducido mediante varias transacciones, en la que están involucrados trabajadores de instituciones financieras.

2. Licuado: hace referencia a la combinación de bienes ilegales con bienes de compañías legales, al final esto se muestra que renta que ha tenido las empresas.

3. Compra de inmuebles y otros: el feriante conoce del origen ilícito del bien, procede a vender mercancías aprecios por encima de su valor real, beneficiándose lucrativa-mente de la diferencia entendida como comisión.

4. Contrabando de dinero: puede manifestarse como traslado físico o electrónico de dinero hacia un país del exterior, esto permite el movimiento de dinero ilegal de una institución bancaria a otra. 
Nixon Manuel Ortega-Carchipulla; Jaime Tinto-Arandes; Judith Cristina Pesantez-Rodriguez; Edwin Joselito Vásquez-Erazo

5. Doble facturación: tiene que ver con la facturación engañosa de importaciones o exportaciones donde se declara valores falsos, aquí el dinero ilegitimo, se muestra como la diferencia entre sobre-facturación y el monto verdadero.

6. Garantías de préstamos: Consentimiento de garantías para posteriormente cumplir con los valores de unos dichos préstamos.

Acorde a lo mencionado anteriormente, el lavado de activos es un problema muy común en nuestro país, cabe indicar que el mismo se incrementó a partir de la dolarización, así lo indica (Acosta, 2000), un término común de esta práctica es el blanqueo, el cual se entiende como las operaciones para cambiar la identidad de beneficios conseguidos de manera ilegal a dinero o bienes de curso legal a través de procesos institucionales patrocinados y legítimamente autorizados, este dinero en un primer momento se asocia a una actividad legal como el comercio, este se fuga del fisco, y luego se introduce el dinero producto de actividades ilícitas.

El lavado de activos según lo indica (Reggiani, 2018), afecta la estabilidad financiera, las actividades de lavado de activos afectan negativamente el progreso de la economía, así como también la competición libre, debido a que los mismos se sustentan en la confianza la cual es un pilar en la "economía de mercado. Con el transcurso de los años se ha evidenciado que la criminalidad organizada se ha infiltrado en la economía legal hasta convertirse en monopolios, cuando los gobiernos no pueden implementar mecanismos de control para el lavado de dinero, estos grupos criminales pueden afectar la demanda de dinero, trayendo con esto altos índices de volatilidad y causando inflación sobre todo en las naciones menos desarrolladas como la nuestra. Las actividades ilícitas que se han involucrado en la economía formal, provienen del narcotráfico, trata de personas, corrupción y terrorismo según (Carrillo, 2017), a nivel internacional, se ha propuesto pautas para combatir el lavado de activos y financiamiento del terrorismo, para esto partimos de la tipificación de estos delitos en todos los países occidentales.

Para luchar con el lavado de activos y el financiamiento del terrorismo (Mariño, et al., 2014), indican que en el año 1989 en Paris se crea la organización de vigilancia global de lavado de dinero, llamada Grupo de Acción Financiera Internacional GAFI 
Nixon Manuel Ortega-Carchipulla; Jaime Tinto-Arandes; Judith Cristina Pesantez-Rodriguez; Edwin Joselito Vásquez-Erazo

este es un grupo intergubernamental que en la actualidad se conforma por 31ñpaíses y dos organismos internacionales; para lo cual presentaron cuarenta recomendaciones enfocadas en impedir la ocupación del sistema financiero para este tipo de operaciones ilegales, en 2001 se incorpora el tema del financiamiento del terrorismo. En lo que respecta a América del Sur se encuentra presente la organización denominada GAFISUD creada en Cartagena Colombia, el 80deldiciembre del año 2000I, tiene estrecha relación con el grupo (GAFI) de manera que se adhirió a sus recomendaciones del GAFI para luchar en contra esa problemática.

El financiamiento del terrorismo según lo indica (Puente, 2018), es un concepto nuevo usado en Ecuador, el mismo hace referencia al acto de proporcionar los fondos o algo de valor para terroristas individuales o grupos terroristas para participar en transacciones financieras. El GAFI (Grupo de Acción financiera Internacional) alienta a los países para criminalizar la financiación del terrorismo, actos terroristas y terroristas de conformidad con el artículo 2 del Convenio contra la financiación de Terrorismo, cabe indicar que esta actividad muestra una mayor dificultad para seguir los rastros de dinero de grupos criminales por dos razones: la primera, debido a la cantidad de fondo requerido para los ataques terroristas es relativamente pequeño y segundo por el financiamiento del terrorismo asignado para la política del grupo y actividades sociales.

Al respecto (Carillo, 2017) da a saber que en nuestro país la disputa en contra del lavado de dinero y el financiamiento del terrorismo, aún es limitada puesto a que en el año 2010 se conoció el aumento en el tráfico ilícito y posesión de drogas, por lo que según la Unidad de Análisis Financiero y Económico, Ecuador fue considerado un país no muy cooperante, además se conoció una supuesta relación con el Banco Central dehlrán (BCl)y de Desarrollo de Exportaciones deklrán (EBDI)I, debido el informe de actividades inhabituales e infundadas por un valor cercano a los \$2,0280millones de dólares.

El lavado de activos y el terrorismo según lo indica (Sulca-Córdova, et al., 2017), muestran similitudes, el primero los fondos iniciales son siempre el resultado de 
Nixon Manuel Ortega-Carchipulla; Jaime Tinto-Arandes; Judith Cristina Pesantez-Rodriguez; Edwin Joselito Vásquez-Erazo

actividades ilegales, mientras que, en segundo, se financian los fondos de forma ilegal, así como legal. Los terroristas usan las mismas técnicas y pasan por las mismas etapas características propias del lavado de dinero para disfrazar la identidad de sus recursos. Sin embargo, el objetivo principal de las personas involucradas en el financiamiento del terrorismo no es necesariamente ocultar la fuente de fondos, un acto terrorista involucra principalmente valores más bajos que aquellos en el caso del lavado de dinero. En este sentido, proponen un modelo de gestión, denominado "Scoring para medir el riesgo de lavado de activos y financiamiento de delitos a personas naturales para empresas del sector público o privado" para esto, se necesita partir del tipo de riesgo detectado.

\section{Tabla 4.}

Clasificación del riesgo.

\begin{tabular}{lll}
\hline Perfil & Criterio & Descripción \\
\hline Tolerable & Bajo Impacto & $\begin{array}{l}\text { Procedimiento admisible o de efecto } \\
\text { menor en el cual no es necesario } \\
\text { algún tipo de seguimiento. }\end{array}$
\end{tabular}

Moderado Impacto Moderado Es preciso hacer controles menores.

Significativo Impacto Significativo

En este tipo de riesgo se necesita hacer un rastreo permanente, examinar si el informe se sustenta con argumentos válidos y de ser necesario requerir la justificación debida al cliente. 
Nixon Manuel Ortega-Carchipulla; Jaime Tinto-Arandes; Judith Cristina Pesantez-Rodriguez; Edwin Joselito Vásquez-Erazo

Crítico Riesgo Alto

Severo Riesgo Extremo
Su seguimiento es imprescindible, en un primer momento se debe solicitar los respectivos justificativos al usuario para posteriormente reportar a los organismos de control correspondientes.

En este riesgo existen claras evidencias de actividades ilícitas, por lo cual se necesita enfrentar a la persona con las pruebas debidas, procurando la mayor sensatez posible.

Fuente: Sulca-Córdova, et al. (2017).

Como se puede apreciar en la tabla 4, el riesgo en lo que respecta a lavado de activos se analiza de acuerdo con su severidad, por lo tanto; (Sulca-Córdova, et al., 2017), afirman que se necesita partir del análisis del movimiento en las transacciones del cliente, tomando como referencia su comportamiento transaccional, producto de sus actividades económicas. Por esto, se recomienda aplicar un proceso oportuno de monitoreo y revisión de este delito tan común en nuestro país. En concordancia a esto (Amat \& Flores, 2015) indican que el monitoreo del riesgo tiene como finalidad comparar su evolución inherente con la del riesgo residual, para esto se debe considerar:

1. Hacer seguimientos, los cuales permitan la pronta identificación y rectificación de las insuficiencias en las etapas de la administración del Riesgo de lavado de activos.

2. Verificar la efectividad de los procesos, políticas, reglamentos y normas, programas y controles internos de la institución; así como también efectuar seguimientos del riesgo inherente y residual de lavado de activos por cada causa de riesgo

3. Instaurar signos de alerta descriptivas y prospectivas que revelen posibles fuentes de riesgo de presencia de dinero ilícito 
Nixon Manuel Ortega-Carchipulla; Jaime Tinto-Arandes; Judith Cristina Pesantez-Rodriguez; Edwin Joselito Vásquez-Erazo

Como se puede apreciar en la gestión de riesgo, las entidades financieras deben iniciar del conocimiento exhaustivo en las actividades comerciales que hacen sus clientes, esto le permitirá determinar el tipo de riesgo al cual se enfrentan. Al respecto (Carrillo, 2017) menciona que una entidad financiera debe tener mecanismos apropiados para documentar y proporcionar información de evaluación de riesgos presentes en su base de datos, las cuales están conformadas por: clientes, productos, canales de entrega y servicios ofrecidos, por lo que nos da a entender que los datos operativos de transacciones específicos, otros informes internos recopilados por la institución esto permitirá controlar adecuadamente aquellas actividades identificadas inherentes riesgos.

Para llevar una gestión adecuada en el riesgo (Amat \& Flores, 2015), recomiendan llevar a cabo un monitoreo continúa, el cual consiste hacer un escrutinio de las transacciones para determinar si las mismas son consistentes con el conocimiento de la entidad financiera sobre el cliente, la naturaleza, el propósito del producto bancario y la relación comercial. Este proceso también implica hacer un seguimiento en el comportamiento en lo que respecta a su actividad económica de modo que su información se encuentre actualizada.

En concordancia a esto (Puente, 2018) acota que la fase de monitoreo debe llevarse a cabo de acuerdo con el tipo de riesgo que se detecte, es así que su intensidad será mayor si el riesgo es alto, y menor si sucede lo contrario, por lo tanto, este tipo de sistema requiere de una adecuación constante de forma continua. El lavado de activos y el financiamiento del terrorismo son delitos sumamente complejos según acota (Grijalva, 2016), los mismos comprometen un buen jurídico que tiene que ver con el orden económico y financiero, sus consecuencias alteran la convivencia social, pues como se indicó anteriormente ocasionan mayor índices inflacionarios al reducir el capital económico circulante dando lugar a una economía paralela que influye en procesos inflacionarios, fomentando situaciones de especulación financieras y monetarias (Reyes, et al., 2020).

En muchas ocasiones según lo indica (Martínez, 2015), las empresas o instituciones financieras consideran erróneamente que la gestión para la prevención de lavado de 
Nixon Manuel Ortega-Carchipulla; Jaime Tinto-Arandes; Judith Cristina Pesantez-Rodriguez; Edwin Joselito Vásquez-Erazo

activos y el financiamiento del terrorismo representan un gasto más, este tipo de mecanismo de prevención a largo plazo no solo representa un ahorro sino permitirá reducir el daño en lo que respecta a la reputación y cualquier tipo de sanción penal. Por esto, contar con una gestión adecuada para prevenir este tipo de delitos según (Amat \& Flores, 2015) trae beneficios como:

1. Mayor sostenibilidad.

2. La confianza sectorial se incrementa.

3. Aumento en la inversión.

4. Incremento de la seguridad en lo que respecta a la gestión empresarial.

5. Afianza la toma de decisiones.

6. La competencia económica se legitima.

Con lo anteriormente dicho la gestión del riesgo en el lavado de activos implica que las empresas e instituciones financieras adquieran un enfocado compromiso en adoptar estrategias enfocadas en hacer un monitoreo constante, pues este tipo de delitos no suele ser identificados a tiempo. En Ecuador se ha planteado luchar con este delito, es así que se promulgó la Ley Reformatoria de la Ley para Reprimir el Lavado de Activos, la cual reemplazó a la Ley por el de Prevención, Detección y Erradicación del Delito de Lavado de Activos y Financiamiento de Delitos, el treinta de diciembrekdel2dosmil diez, mediante Registro Oficial Suplemento No.0352. De igual forma cabe indicar que este delito está tipificado en el Código Orgánico Integral Penal.

\section{La lógica difusa como herramienta de análisis}

El concepto de lógica difusa según lo indica (Cruz-Martínez \& Alarcón-Armenteros, 2017) fue propuesto por Zadeh en el año de 1965, la misma hacía referencia a cierto grado de incertidumbre en los procesos, los cuales están emparejados con percepciones humanas, dejando de lado el uso de modelos matemáticos convencionales, y por el contrario se dio prioridad a modelos alternativos basados en variables lingüísticas. Sin embargo, dio importancia a una expresión neutral donde no existe la falsedad ni certeza absoluta, mostrando así su vaguedad conceptual. 
Nixon Manuel Ortega-Carchipulla; Jaime Tinto-Arandes; Judith Cristina Pesantez-Rodriguez; Edwin Joselito Vásquez-Erazo

Al respecto (González, 2011) indica que el concepto de lógica difusa tiene un significado extenso, se necesita indicar que el mismo que se encuentra asociado a cuantificadores, reglas y a la aritmética difusa, también guardan relación con la probabilidad debido a que comparten información sobre la frecuencia de ocurrencias relativas de un evento bien definido. Por su parte, Bonilla (2016) afirma que en su primer momento la lógica difusa persiguió la finalidad de medir el grado de verdad o falsedad, aplicando una escala entre 1 y 0 ésta se caracterizó porque intervino la imprecisión y la incertidumbre, como ejemplo el estudio de un profesor del Departamento de Ingeniería Eléctrica y la Ciencia de la Computación de la Universidad de California, dio a saber que la característica la lógica difusa, fue que dio paso el uso de la lengua natural (espontáneo) enfrentándose con la imprecisión, acercándose a la intuición humana.

A continuación se dará a conocer los ámbitos donde se ha implementado la lógica difusa, por ejemplo, (Cruz-Martínez \& Alarcón-Armenteros, 2017) indican que en América Central se desarrolló una investigación la cual fue aplicada al sector manufacturero la misma que se realizó utilizando la opinión de directivos se determinó la capacidad para medir de forma satisfactoria la confianza industrial y el clima empresarial; con los resultados, se aportó a un mejor entendimiento de las opiniones y actitudes de la clase industrial trabajadora.

En concordancia a esto, (González, 2011) permitió conocer un ejemplo de lógica difusa en España en el cual se implementó un modelo de control borroso que ayudó a la creación y desarrollo una nueva iniciativa empresarial; esto aportó al mejoramiento en la aceptación del criterio de los evaluadores, pues los mismos se sintieron más se cómodos al expresar sus opiniones mediante razonamientos lingüísticos. Así también en Cuba se efectuó un estudio sobre las herramientas de lógica difusa para tomar decisiones en tareas del Sistema Nacional de Salud; a través de una revisión bibliográfica y documental, se obtuvo como resultado que las herramientas aplicadas en el sector de la salud no resultan útiles en su gestión (CalleAbril, et al., 2020). 
Nixon Manuel Ortega-Carchipulla; Jaime Tinto-Arandes; Judith Cristina Pesantez-Rodriguez; Edwin Joselito Vásquez-Erazo

La lógica difusa en el ámbito financiero según lo indican (Díaz-Córdova, et al., 2017) tiene que ver con la aplicación de sistemas que aportan a la medición del desempeño enfocadas en mejorar las calificaciones crediticias y su nivel de riesgo, a través de la incertidumbre la cual se basa en la medición entre los valores entre 0 y 1 , lo que permite dar a conocer resultados con una perspectiva más amplia, los cuales se mostrarán no totalmente ciertos ni totalmente falsos, y esto permitirá obtener una cuantía indistinta de veracidad dentro de un grupo de cuantías (Vidal, et al., 2019). Un modelo de lógica difusa aplicada a la prevención en el delito de lavado de activos y financiamiento del terrorismo según lo indican (Cruz-Martínez \& AlarcónArmenteros, 2017) estaría acorde al nivel de exposición al riesgo operacional, para esto se requiere de determinar variables cualitativas que intervienen en este tipo de riesgo, esto permitirá conocer a cabalmente la complejidad de la actividad económica así como también las fortalezas del ambiente de control con esto se disminuirá la amenaza del riesgo (Ortega, et al., 2019).

La utilidad de la lógica difusa para prevenir el lavado de activos y el financiamiento del terrorismo según (Díaz-Córdova, et al., 2017) es la comprobación en los niveles de pertenencia para el segmento cooperativo; obtuvieron niveles entre bueno y muy bueno. Lo cual nos indica que presentan muy buenos factores de protección y su calidad de crédito se ubica en categorías superiores, no obstante, sus factores de riesgo son moderados pero las épocas de poca actividad económica pueden llegar a afectar su puntaje.

\section{METODOLOGÍA}

Metodológicamente se desarrolló un tipo descriptiva con diseño de campo no experimental, transversal, observándose las variables tal como ocurren en la realidad, mediante encuesta y cuestionario aplicado en un único momento investigativo, en una muestra de 87 personas que laboran en entidades financieras que se encuentran en la escala $A A$ en la ciudad de Cuenca, específicamente del departamento de cumplimiento, servicios bancarios y los oficiales de negocios, procesándose los datos mediante estadística descriptiva. 
Nixon Manuel Ortega-Carchipulla; Jaime Tinto-Arandes; Judith Cristina Pesantez-Rodriguez;

Edwin Joselito Vásquez-Erazo

\section{RESULTADOS}

Los resultados que se obtuvieron mediante el uso de instrumento de investigación al personal de una de las instituciones financieras que se encuentra en la calificación de riesgo AA de la ciudad de Cuenca, se presenta a continuación:

\section{Conceptos generales}

El personal de las entidades financieras deben tener conocimiento generales sobre el lavado de activos, lo cual permitirá a las instituciones financieras minimizar el riesgo al que se exponen atreves de las diferentes tipologías que se utiliza por el crimen organizado para ingresar dinero o bienes producto de actividades ilícitas. Como resultado se puede evidenciar en el gráfico adjunto que un $96.6 \%$ indican si conocen dicho concepto y el $3.4 \%$, no tiene conocimiento del mismo.

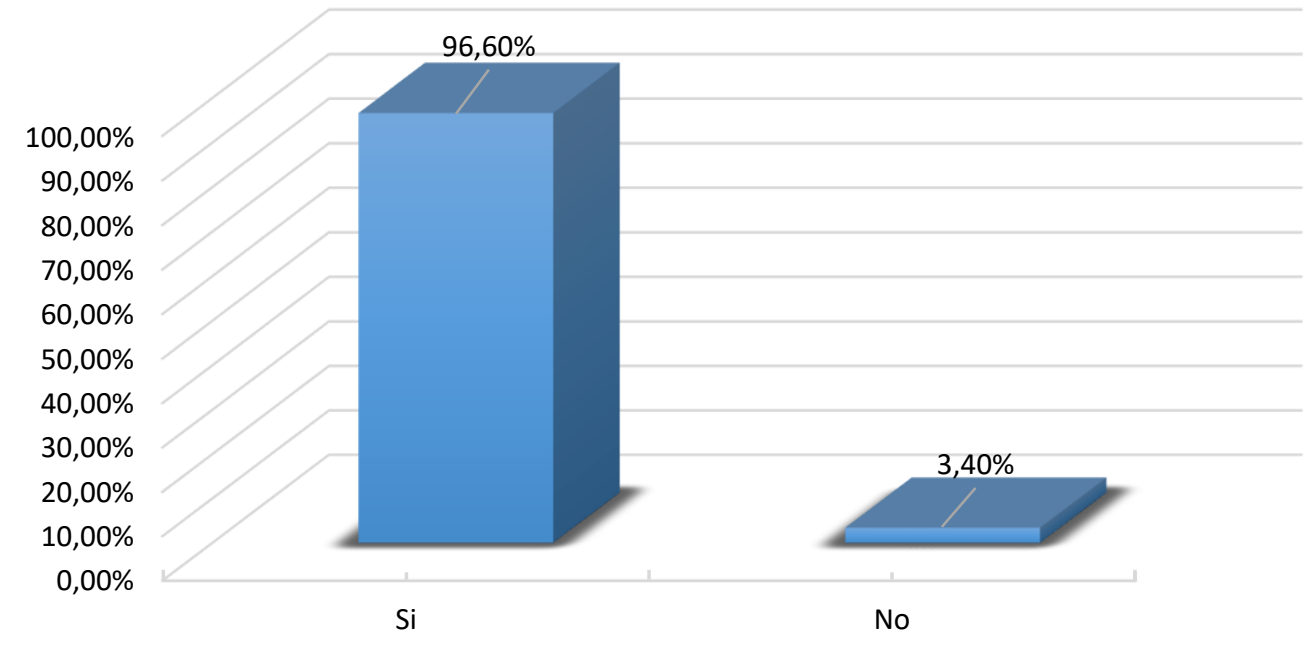

Figura 1. ¿Sabe usted que es el lavado de activos?

Fuente: Investigaciones de campo. 
Nixon Manuel Ortega-Carchipulla; Jaime Tinto-Arandes; Judith Cristina Pesantez-Rodriguez; Edwin Joselito Vásquez-Erazo

\section{Procedimientos Instituciones Financieras}

Los procedimientos que se ejecutan en las instituciones financieras son importantes por cuanto los mismos permiten el cumplimiento de las políticas, y objetivos de la institución. Por lo expuesto se presentan los resultados siguientes en el gráfico adjunto:

1. En referencia a la pregunta, si el banco Brinda las herramientas suficientes para cumplir con sus labores eficientemente un $64,4 \%$ indica que no cuentan con las herramientas adecuadas para cumplir su labor eficientemente.

2. En relación con la obtención de información del cliente $61.5 \%$, depende mucho, de la información que el cliente, este presto a proporcionar al momento del acercamiento en el proceso de vinculación a la institución.

3. En consideración del manejo del sistema del banco refleja que $62.10 \%$ es fácil de administrar.

4. En atención a la pregunta si la información con la cual se cuenta en los sistemas de la institución permiten una adecuada toma de decisiones $50.60 \%$ apuntaron probablemente no, y.

5. En el resultado reflejado si la institución cuenta con información suficiente para el análisis de los clientes un $50.40 \%$ respondieron probablemente no.

6.

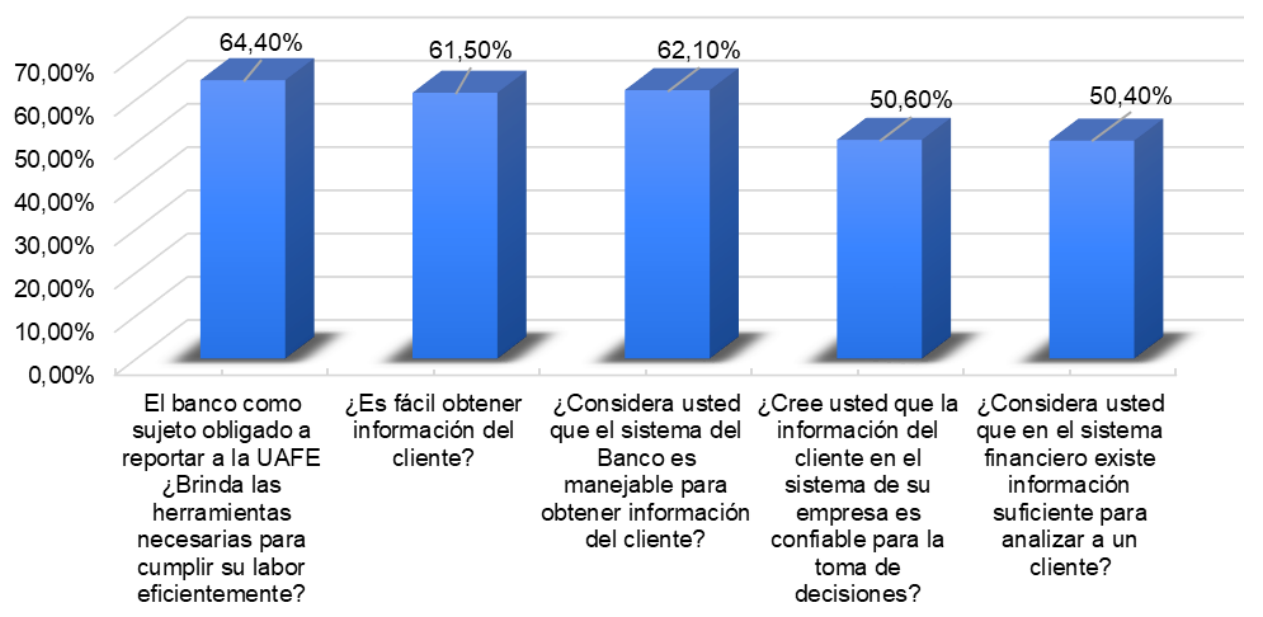

Figura 2. Procedimientos instituciones financieras.

Fuente: Investigaciones de campo. 
Nixon Manuel Ortega-Carchipulla; Jaime Tinto-Arandes; Judith Cristina Pesantez-Rodriguez; Edwin Joselito Vásquez-Erazo

\section{Procedimientos Normativos}

El cumplimiento de los procedimientos normativos es importancia dentro de las instituciones financieras las mismas que están obligadas a cumplir con las disipaciones contenidas en la codificación de la Superintendencia de Bancos así como también en la ley orgánica de prevención detección y erradicación del delito del lavado de activos y del financiamiento de delitos, por lo expuesto como resultado se puede evidenciar lo siguiente:

1. El $69 \%$ de los encuestados señalan que cumplen con la obtención de la información del origen de los fondos de los clientes

2. El $87.4 \%$ indican como un proceso mensual de actualización de información de los clientes en cumplimiento, a lo que está estipulado a la norma vigente.

3. El $78.20 \%$, informan que avances cumplen con el proceso de validación de la información.

4. $85.10 \%$ indican que se generan alertas, considerándose falsos positivos por falta de información de los clientes, lo cual desvirtúa el perfil de riesgo real del cliente.

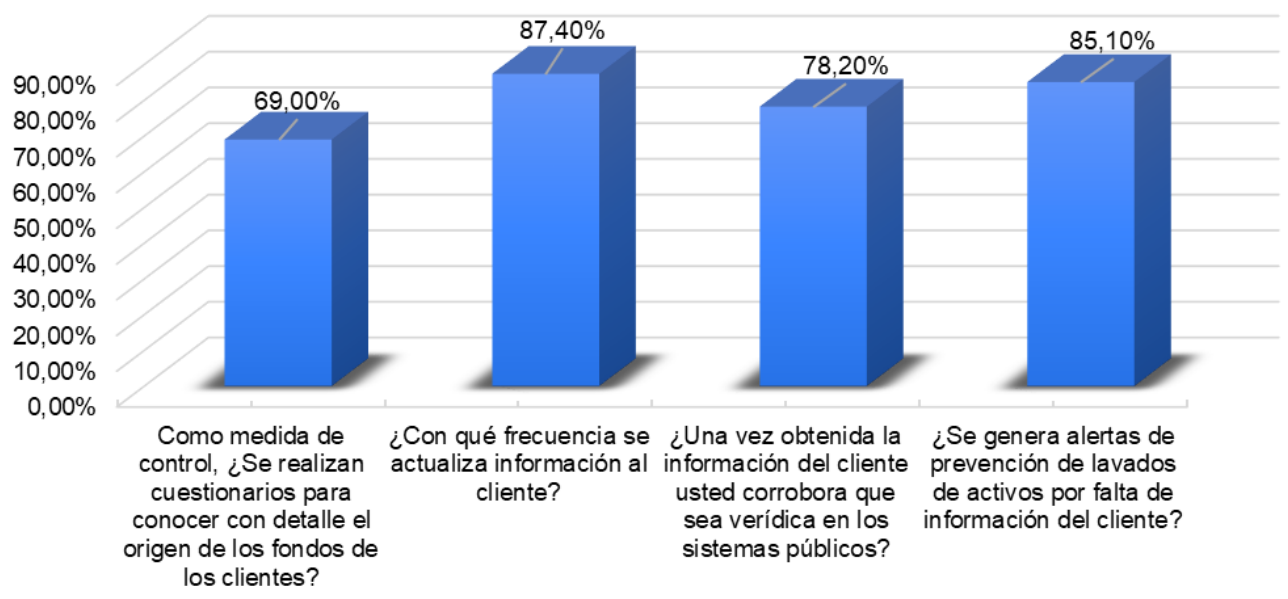

Figura 3. Procedimientos normativos.

Fuente: Investigaciones de campo. 
Nixon Manuel Ortega-Carchipulla; Jaime Tinto-Arandes; Judith Cristina Pesantez-Rodriguez; Edwin Joselito Vásquez-Erazo

Como resultado de las encuestas realizadas se puede evidenciar que existen deficiencias para cumplir una de las políticas más importantes cómo es, la política conozca a su cliente, como consecuencia de las debilidades identificadas se presentan las siguientes incidencias:

1. Inadecuada definición de perfil de riesgo de los clientes

2. Generación de alertas falsas en el sistema por falta de información de los clientes.

3. Dificultad de los oficiales de negocios en la aplicación de las debidas diligencias de los clientes.

4. Carga operativa en el seguimiento de operaciones que no ameriten un análisis.

\section{Propuesta}

Una vez finalizado la indagación de los resultados que se adquirieron del presente estudio, el propósito, es evitar que las instituciones financieras sean utilizadas atreves de sus productos y servicios para ingresar dinero de actividades ilícitas, por medio de la relación contractual con los clientes.

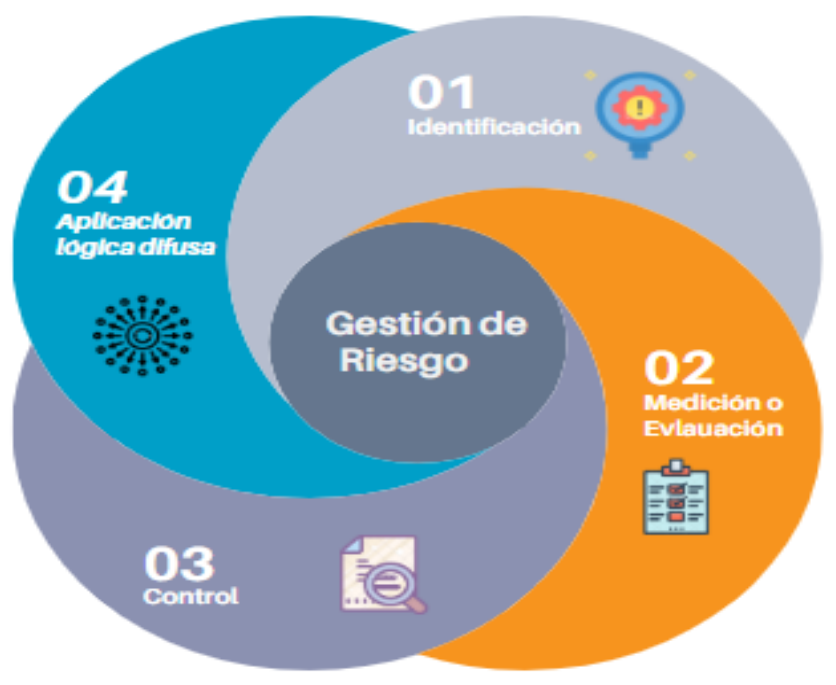

Figura 4. Propuesta/ gestión de riesgo.

Fuente: Elaboración propia. 
Nixon Manuel Ortega-Carchipulla; Jaime Tinto-Arandes; Judith Cristina Pesantez-Rodriguez; Edwin Joselito Vásquez-Erazo

\section{Identificar}

En esta primera fase se busca identificar el riesgo a administrar dentro de las entidades financieras, por lo cual el análisis de una identificación debe ser amplia, aplicando un proceso sistemático bien organizado. La metodología de la gestión de riesgo al LA/FT, debe permitir a los bancos financieros identificar los riesgos de LA/FT inherentes a su actividad económica, para la cual se deberán considerar los siguientes factores de riesgo:

- Factor cliente

- Factor productos y servicios

- Factores canales de distribución

- Factor geográfico o jurisdicción

Para la presente investigación, se consideró el factor cliente, el mismo que se propone segmentar a los clientes en personas naturales y jurídicas en la cual comprendería: línea de negocio y segmento, como se puede observar en el cuadro siguiente.

- Persona natural. Se considera como una persona responsable en pleno uso de sus facultades mentales y derechos civiles

- Persona jurídica. Se considera a un individuo o entidad, reconocidos legalmente, susceptible a contraer derechos y obligaciones, tanto de propiedad pública o privada. 


\begin{tabular}{|c|c|c|c|}
\hline \multirow{7}{*}{ 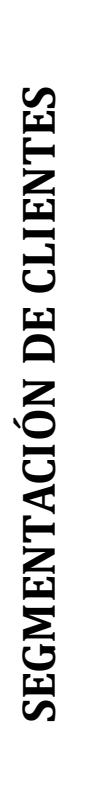 } & Tipo de cliente & Linea de Negocio & Segmento \\
\hline & \multirow{2}{*}{ Persona Natural } & $\begin{array}{l}\text { Empresas } \\
\text { Personas }\end{array}$ & $\begin{array}{c}\text { Empresarial } \\
\text { Personal }\end{array}$ \\
\hline & & Microfinanzas & Micro Finanzas \\
\hline & \multirow{4}{*}{ Persona Juridica } & \multirow{3}{*}{ Empresas } & Empresarial \\
\hline & & & Sector Publico \\
\hline & & & IFIS \\
\hline & & Microfinanzas & Micro Finanzas \\
\hline
\end{tabular}

Figura 5. Segmentación de clientes.

Fuente: Elaboración propia.

\section{Medición o Evaluación}

Una vez finalizada la etapa de identificación, que se consideró en este estudio, se procede a la medición del factor de riesgo cliente que tendrá como apoyo la segmentación antes mencionada, la cual permite determinar su perfil y exposición al riesgo inherente, por lo que se sugiere señalar rangos de puntuación numéricas, tanto a la posibilidad como probabilidad de ocurrencia de lavado de activos y financiamiento de terrorismo en el factor cliente, por ende nos ayudará a medir el impacto en apoyo a su materialidad a través de los riesgos agrupados.

1. Para medir la probabilidad de ocurrencia del riesgo de LA/FT, consiste en asignar un rango de calificación numérico a cada uno de los eventos de riesgos identificados y esto nos ayudará a reflejar la probabilidad de ocurrencia del mismo.

Para medir la probabilidad de un riesgo de lavado de activos y financiamiento de delito en las entidades financieras se consideran las siguientes escalas 
Nixon Manuel Ortega-Carchipulla; Jaime Tinto-Arandes; Judith Cristina Pesantez-Rodriguez; Edwin Joselito Vásquez-Erazo

\begin{tabular}{|c|c|}
\hline \multicolumn{2}{|c|}{$\begin{array}{c}\text { Probabilidades de ocurrencia } \\
\text { de riesgo LA/FT }\end{array}$} \\
\hline Rango & Valor \\
\hline Rara vez & 1 \\
\hline Posible & 2 \\
\hline Probable & 3 \\
\hline Ocasional & 4 \\
\hline Inminente & 5 \\
\hline
\end{tabular}

Figura 6. Probabilidades de ocurrencia de riesgo LA/FT. Fuente: Elaboración propia.

Rara vez: Podría ocurrir en muy poca frecuencia. Se desconoce algún caso donde que el segmento cliente haya sido utilizado para el lavado de activos.

Posible: Podría ocurrir alguna vez. En esta existe, la probabilidad de que ocurra y se ha dado en otros países. No es muy conveniente hacerlo para actividades de lavado de activos

Probable: Podría cumplirse en situaciones actuales.

Ocasional: Podría suceder de forma accidental, la cual ocurre en condiciones presentes al momento en que se ejecuta.

Inminente: Significa que está a punto de ocurrir en un próximo evento.

2. Para medir el impacto que ocurre en el riesgo de lavado de activos y financiamiento de terrorismo se debe fijar una puntuación a cada uno de los eventos de riesgos que se identificaron que reflejara el efecto de llegar a materializarse dichos eventos.

Para medir el impacto de riesgo de LA/FT, se consideran las siguientes escalas: 
Nixon Manuel Ortega-Carchipulla; Jaime Tinto-Arandes; Judith Cristina Pesantez-Rodriguez; Edwin Joselito Vásquez-Erazo

\begin{tabular}{|c|c|}
\hline \multicolumn{2}{|c|}{ Impacto si ocurre el riesgo } \\
LA/FT \\
\hline Rango & Valor \\
\hline No significativo & 1 \\
\hline Menor & 2 \\
\hline Moderado & 3 \\
\hline Significativo & 4 \\
\hline Catastrofico & 5 \\
\hline
\end{tabular}

Figura 6. Impacto si ocurre el riesgo LA/FT.

Fuente. Elaboración propia.

No significativo: Tener un efecto nulo en las entidades financieras.

Menor: Daño el patrimonio de las entidades financieras, se puede corregir a corto plazo.

Moderado: Ocasionaría perdidas en su patrimonio, y daño en la imagen de las entidades financieras, y para poder corregir el daño se necesitaría de un largo plazo. Significativo: Daños significativos en el patrimonio e imagen de las entidades financieras.

Catastrófico: Actúa directamente en la ejecución de la misión, perdida del patrimonio, daños en la imagen, sanciones económicas y paralización de actividades temporales.

3. El resultado del riesgo inherente del segmento del "riesgo cliente" se obtiene de la siguiente manera:

\begin{tabular}{|c|c|c|c|c|c|c|c|}
\hline & & & \multicolumn{5}{|c|}{ MATRIZ DE PROBABILIDAD E IMPACTO } \\
\hline \multirow{5}{*}{ 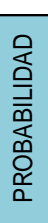 } & 空兽 & 5 & 5 & 10 & 15 & 20 & 25 \\
\hline & 을 횽 & 4 & 4 & 8 & 12 & 16 & 20 \\
\hline & 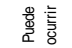 & 3 & 3 & 6 & 9 & 12 & 15 \\
\hline & 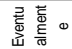 & 2 & 2 & 4 & 6 & 8 & 10 \\
\hline & 蹗的萝 & 1 & 1 & 2 & 3 & 4 & 5 \\
\hline & & & 1 & 2 & 3 & 4 & 5 \\
\hline & & & Baja & Menor & Moderado & Mayor & Alto \\
\hline
\end{tabular}

Figura 7. Riesgo inherente= Probabilidad X Impacto.

Fuente: Elaboración propia. 
Nixon Manuel Ortega-Carchipulla; Jaime Tinto-Arandes; Judith Cristina Pesantez-Rodriguez; Edwin Joselito Vásquez-Erazo

\section{Control}

Para minimizar el riesgo inherente de LA/FT, se tiene que identificar, evaluar y vigilar los controles existentes o definir nuevos controles con el fin de mitigar la probabilidad o impacto de llegar a concretarse los eventos de riesgo identificados.

Para poder vigilar si es efectivo, los controles implementados se utilizaran la siguiente escala de valoración:

\begin{tabular}{|c|c|}
\hline \multicolumn{2}{|c|}{ Efectividad } \\
\hline RANGO & VALOR \\
\hline Adecuado & 5 \\
\hline $\begin{array}{c}\text { Moderadamente } \\
\text { adecuado }\end{array}$ & 4 \\
\hline Necesita mejoras & 3 \\
\hline Débil & 2 \\
\hline Inadecuado & 1 \\
\hline
\end{tabular}

Figura 8. Efectividad.

Fuente: Elaboración propia.

Adecuado: Los controles implementados descartan la probabilidad de ocurrencia, reduciendo a muy bajo

Moderadamente, adecuado: Los controles implementados limitan la probabilidad de ocurrencia, reduciendo a "bajo".

Necesita mejorar: Los controles implementados limitan, pero no del todo, existe probabilidad de que ocurra, igualmente reduciéndole a "bajo".

Débil: Los controles implementados reflejan fragilidad significativa.

Posterior a esto se debe calcular el riesgo residual por la cual utilizaremos la siguiente formula:

Riesgo inherentes - Control $=$ Riesgo residual 
Una vez obtenido el riesgo residual permite a las instituciones financieras tomar las mejores decisiones para minimizar.

La escala que servirá como referencia para considerar las acciones a tomar será la siguiente.

\begin{tabular}{|c|c|c|}
\hline \multicolumn{3}{|c|}{ VALORACIÓN DEL RIESGO } \\
\hline RIESGO RESIDUAL & VALOR & RANGO \\
\hline $1-5$. & 1 & BAJO \\
\hline $6-2$. & 2 & MODERADO \\
\hline $13-18$ & 3 & MAYOR \\
\hline $19-25$ & 4 & ALTO \\
\hline
\end{tabular}

Figura 9. Valoración de riesgo.

Fuente. Elaboración propia.

\section{Aplicación de la lógica difusa}

En esta etapa se plantea implementar la aplicación de la lógica difusa que permitirá un seguimiento sistemático, permanente y efectivo que facilitará la detección rápida y corrección de las deficiencias de la gestión de riesgos de LA/FT. Se partirá del análisis de la información cualitativa y cuantitativa de toda la base de clientes que mantienen cada institución financiera que permitirá segmentar de acuerdo con las características de los clientes, por lo que se tomará en cuenta conocimiento del cliente (antigüedad), Ingresos, Edad, actividad económica, nacionalidad. En esta fase permitirá aportar una calificación de riesgo que nos ayudará a cuantificar el riesgo de los clientes y permitirá una gestión adecuada y debida diligencia de los mismos.

\section{CONCLUSIONES}

La gestión de riesgo en el sistema financiero es un desarrollo continuo relacionado con el conocimiento, evaluación, manejo de los riesgos, sus impactos esto nos ayuda a tener una mejor toma de decisiones e identificar, valorar y manejar los riesgos dentro de las entidades financieras, una vez ejecutado correctamente ayudará encontrar 
Nixon Manuel Ortega-Carchipulla; Jaime Tinto-Arandes; Judith Cristina Pesantez-Rodriguez; Edwin Joselito Vásquez-Erazo

soluciones reales, también permitirá contar con información a la alta gerencia o administradores de las instituciones financieras, para toma de decisiones en cuanto a un cambio para mejorar su infraestructura tecnológica, procesos, generación de alertas en otros.

Una adecuada gestión de riesgo en las instituciones financieras les permitirá minimizar el riesgo de verse involucrados en casos de clientes, relacionado con el lavado de activos. Al mismo tiempo les ayudará a proteger a las instituciones de sanciones por parte de los organismos de control y proteger su imagen en el mercado financiero. Las políticas y procedimientos del manual de lavado de activos y financiamiento de delitos como el terrorismo deben estar involucrados todos los funcionarios de las instituciones financieras, para lograr una integra comprensión y correcta aplicación en las labores diarias para dejar resultados óptimos.

\section{FINANCIAMIENTO}

No monetario

\section{AGRADECIMIENTO}

A las instituciones financieras que se encuentra en la calificación de riesgo AA de la ciudad de Cuenca; por el apoyo en el desarrollo de la investigación.

\section{REFERENCIAS CONSULTADAS}

Acosta, A. (2000). La trampa de la dolarización. [The dollarization trap]. En Acosta, A, \& Juncosa, J. Dolarización Informe Urgente. [Urgent Report Dollarization]. Recuperado de https://n9.cl/bx2t

Amat, M., \& Flores , C. (2015). La Gestión de Riesgo sobre el lavado de activos aplicado a compañías fiduciarias. [Risk Management on money laundering applied to trust companies]. Recuperado de https://n9.cl/ndtw

Amores, F. (2016). Administración del Riesgo de Lavado de Activos y de la Financiación del Terrorismo en Instituciones Financieras, caso Corporación Financiera Nacional. [Risk Management of Money Laundering and Terrorism Financing in Financial Institutions, case of the National Financial Corporation]. Recuperado de https://n9.cl/h8ts 
Nixon Manuel Ortega-Carchipulla; Jaime Tinto-Arandes; Judith Cristina Pesantez-Rodriguez; Edwin Joselito Vásquez-Erazo

Bermeo, F. (2015). Ecuador en el circuito de lavado de activos. [Ecuador in the money laundering circuit]. Perfil Criminológico $\mathrm{N}^{\circ} 15$. Recuperado de https://n9.cl/zhw0

Bonilla, J. (2016). Toma de decisiones a través de la lógica borrosa en el Sector Cooperativo. [Decision making through fuzzy logic in the Cooperative Sector]. Recuperado de https://n9.cl/ut0b

Calle-Abril, D. R., Erazo-Álvarez, J. C., \& Narváez-Zurita, C. I. (2020). Estrategias de mediación y solución de conflictos para el sector industrial de pinturas [Mediation and conflict resolution strategies for the paint industry]. Revista Arbitrada Interdisciplinaria Koinonía, 10(5), 514-544. http://dx.doi.org/10.35381/r.k.v5i10.704

Carillo, P. (2017). Sistema de control de gestión de riesgo para la prevención del lavado de activos en la cooperativa de ahorro y crédito Sumak Samy Ltda. En la ciudad de Ambato. [Risk management control system for the prevention of money laundering in the savings and credit cooperative Sumak Samy Ltda. In the city of Ambato]. Recuperado de https://n9.cl/yl1p

Cruz-Martínez, A, \& Alarcón-Armenteros, A. (2017). La lógica difusa en la modelización del riesgo operacional. Una solución desde la inteligencia artificial en la banca cubana. [Fuzzy Logic to Model Operational Risk: A Solution Based on Artificial Intelligence in the Cuban Banking]. Cofin Habana, 11(2), 122-135.

Díaz-Córdova, J., Coba-Molina, E., \& Navarrete, P. (2017). Lógica difusa y el riesgo financiero. Una propuesta de clasificación de riesgo financiero al sector cooperativo. [Fuzzy logic and financial risk. A proposal for the classification of financial risk to the cooperative sector]. Contaduría y Administración, 62(5), 1670-1686. http://dx.doi.org/10.1016/j.cya.2017.09.001

González, C. (2011). Lógica Difusa. Una introucción práctica. [Diffuse logic. A practical introduction]. Recuperado de https://n9.cl/8byg

Grijalva, D. (2016). Gestión de riesgo para la prevención de lavado de activos en bancos nacionales privados de actividad comercial del sistema financiero ecuatoriano. [Risk management for the prevention of money laundering in private national banks of commercial activity of the Ecuadorian financial system]. Recuperado de https://n9.cl/eobl

Mariño , G., Chaparro, F., \& Medina , I. (2014). Determinantes en la prevención del riesgo para el lavado de activos y la financiación del terrorismo (LA/FT) en el sector real. [Determinants of Risk Prevention for Money Laundering and Terrorist Financing (ML/TF) in Real Sector]. Recuperado de https://n9.cl/7r6p 
Nixon Manuel Ortega-Carchipulla; Jaime Tinto-Arandes; Judith Cristina Pesantez-Rodriguez; Edwin Joselito Vásquez-Erazo

Martínez, I. (2015). Prevención del lavado de activos y financiamiento del terrorismo. Impactos en los sujetos obligados a informar. [Prevention of money laundering and financing of terrorism. Impacts on the subjects obliged to report. Recuperado de https://n9.cl/k28t

Ortega, O. F., Erazo, J. C., \& Narváez, C. I. (2019). Evaluación técnica y financiera de proyectos productivos aplicando lógica difusa [Technical and financial evaluation of productive projects applying fuzzy logic]. Cienciamatria, 298-327. https://doi.org/10.35381/cm.v5i1.268

Ortega-Iñiguez, O., Erazo-Álvarez, J., \& Narváez-Zurita, C. (2019). Evaluación técnica y financiera de proyectos productivos aplicando lógica difusa. [Technical and financial evaluation of productive projects applying fuzzy logic]. CIENCIAMATRIA, 5(1), 298-327. https://doi.org/10.35381/cm.v5i1.268

Puente, A. (2018). Gestión de riesgo para la prevención de lavado de activos en cooperativas de ahorro y crédito, caso práctico cooperativa de ahorro y crédito de la PUCE. [risk management for the prevention of washing assets in savings and credit cooperatives, case savings and credit cooperative practice PUCE]. Recuperado de https://n9.cl/9y2s

Reggiani, C. (2018). Lavado de activos. [Money laundering]. Recuperado de https://n9.cl/9j32u

Reyes, P. E., Narváez, C. I., Erazo, J. C., \& Giler, L. V. (2020). Configuración del impuesto a la patente municipal con base al ingreso de las actividades económicas. Caso: GAD Municipal de Pucará - Ecuador. [Configuration of the municipal license tax based on income from economic activities. Case: Municipal GAD of Pucará - Ecuador]. Revista Espacios, 41(21), 197-211.

Romero, B. (2015). La Estructura del Sistema Financiero Ecuatoriano. [The Structure of the Ecuadorian Financial System]. Recuperado de https://n9.cl/lewca

Soler-González, R., Varela-Lorenzo, P., Oñate-Andino, A., \& Naranjo-Silva, E. (2018). La gestión de riesgo: el ausente recurrente de la administración de empresas. [Risk management: the recurrent absence of business administration]. CIENCIA UNEMI, 11(26), 51-62. https://doi.org/10.29076/issn.2528-7737vol11iss26.2018pp51-62p 
Nixon Manuel Ortega-Carchipulla; Jaime Tinto-Arandes; Judith Cristina Pesantez-Rodriguez; Edwin Joselito Vásquez-Erazo

Sulca-Córdova, G. C., Espinoza-Beltrán, Y. V., \& Becerra-Paguay, E. R. (2017). Scoring para medir el riesgo de lavado de activos y financiamiento de delitos a personas naturales para empresas del sector público o privado. [Scoring to measure the risk of money laundering and financing of crimes against natural persons for companies in the public or private sector]. Revista Publicando, 4(12 (2), 68-87.

Superintendencia de Bancos. (2019). Calificación de Riesgo Instituciones Financieras 2019. [Financial Institutions Risk Rating 2019]. Recuperado de https://n9.cl/vnon

Uribe, R. (2003). Cambio de paradigmas sobre el lavado de activos. [Paradigm Shift on Money Laundering]. Recuperado de https://n9.cl/skmw

Vidal, K., Erazo, J., \& Narváez, C. (2019). La lógica difusa como herramienta de evaluación financiera de proyectos de inversión. [Fuzzy logic as a tool for financial evaluation of investment projects]. Revista Arbitrada Interdisciplinaria Koinonía, 1(49, 309-348. http://dx.doi.org/10.35381/r.k.v4i1.460

\footnotetext{
(C2020 por los autores. Este artículo es de acceso abierto y distribuido según los términos y condiciones de la licencia Creative Commons Atribución-NoComercial-Compartirlgual 4.0 Internacional (CC BY-NC-SA 4.0) (https://creativecommons.org/licenses/by-nc-sa/4.0/).
} 